\title{
Application and Comparison Between the Conventional Methods and PSO Method for Maximum Power Point Extraction in Photovoltaic Systems Under Partial Shading Conditions
}

\author{
Bennis Ghita ${ }^{1}$, Karim Mohammed ${ }^{2}$, Lagrioui Ahmed ${ }^{3}$ \\ ${ }^{1,2}$ LISTA Laboratory, Faculty of Sciences Dhar El Mahraz, Sidi Mohammed Ben Abdellah University Fès, Morocco \\ ${ }^{3}$ Department of Electrical Engineering And Computer Engineering, National School of Arts and Métiers, University \\ Moulay Ismail Meknes - Morocco
}

\begin{tabular}{l}
\hline Article Info \\
\hline Article history: \\
Received Jan 11, 2018 \\
Revised Apr 10, 2018 \\
Accepted Apr 24, 2018 \\
\hline
\end{tabular}

Keyword:

Fuzzy logic

MPPT

P\&O

PV Array

\begin{abstract}
Several algorithms have been offered to track the Maximum Power Point when we have one maximum power point. Moreover, fuzzy control and neural was utilized to track the Maximum Power Point when we have multipeaks power points. In this paper, we will propose an improved Maximum Power Point tracking method for the photovoltaic system utilizing a modified PSO algorithm. The main advantage of the method is the decreasing of the steady state oscillation (to practically zero) once the Maximum Power Point is located. moreover, the proposed method has the ability to track the Maximum Power Point for the extreme environmental condition that cause the presence of maximum multi-power points, for example, partial shading condition and large fluctuations of insolation. To evaluate the effectiveness of the proposed method, MATLAB simulations are carried out under very challenging circumstance, namely step changes in irradiance, step changes in load, and partial shading of the Photovoltaic array. Finally, its performance is compared with the perturbation and observation" and fuzzy logic results for the single peak, and the neural-fuzzy control results for the multi-peaks.
\end{abstract}

Copyright ( ${ }^{\circ} 2018$ Institute of Advanced Engineering and Science. All rights reserved.

Corresponding Author:

Bennis Ghita,

LISTA Laboratory

Sidi Mohammed Ben Abdellah University Fès

Faculty of Sciences Dhar El Mahraz, Morocco

Email: ghita.bennis@usmba.ac.ma

\section{INTRODUCTION}

Solar energy is alternative source of energy of high importance. For this many research efforts have been concentrated on improving the efficiency of photovoltaic (PV) systems and accessibility of this technology. The PV system is built utilizing one or more panels. the power converter is utilized as an interface amongst the photovoltaic array and the load, which admits a Maximum Power Point (MPP) at a precise load value. This last is not stable and fixe, it subit changes as parameters change the comportment of the photovoltaic system, such as solar radiation. What makes it essential to search for a control technique which consists in adjusting on the duty cycle of the converter in order to pursuit the MPP. This research presents an intelligent approach to be able to pursuit the Maximum Power Point with the aid of technologies founded on particle swarm optimization (PSO) algorithm. In this works we will propose an improved maximum power point tracking (MPPT) method for the PV system using a modified PSO algorithm. the results got from this algorithm will be compared with the Perturb and Observe and fuzzy logic algorithms for the single peak characteristics of the P-V. A similar comparison is done for the multi-peak characteristic of the P-V between the PSO and neural-fuzzy logic algorithms [1-2]. 


\section{MODELING OF THE PHOTOVOLTAIC PANEL}

\subsection{Model of a photovoltaic cell}

The equivalent circuit of a photovoltaic cell is given in Figure 1 Maintaining the Integrity of the Specifications

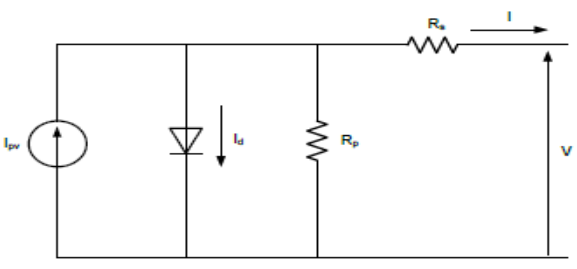

Figure 1. Equivalent Circuit of a Photovoltaic Cell.

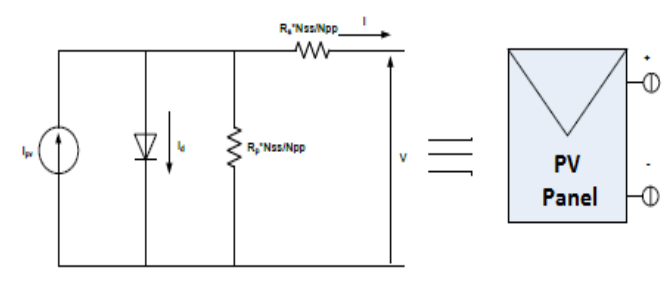

Figure 2. An Equivalent Circuit of a Photovoltaic Field

The equivalent circuit of Figure 1 is composed of a controlled current source which models the effect Photovoltaic (the current generated is controlled by the solar illumination). The diode represents the effect of The semiconductor junction of the cell (models use two diodes in parallel for more precision). Two resistors (Rs, Rp), one in series and the other in parallel, produce the resistivity effect In the cell[1].

The current source in Figure 1 is controlled by illumination and temperature:

$$
I_{p v}=\left(I_{p v, n}+K_{I} \Delta_{T}\right) \frac{G}{G_{n}}
$$

Or

Ipv, $\mathrm{n}$ is the nominal current (given under nominal conditions: $\mathrm{T}=25^{\circ} \mathrm{C}$ and $\mathrm{G}=1000 \mathrm{~W} / \mathrm{m} 2$ ), $\mathrm{KI}$ is the Short-circuit current / temperature coefficient, $\Delta \mathrm{T}=\mathrm{T}-\mathrm{Tn}$ ( $\mathrm{T}$ and $\mathrm{Tn}$ are the current and nominal temperature Respectively), $\mathrm{G}$ and $\mathrm{Gn}$ are the current and nominal illumination. The current in the diode is given by:

$$
I_{d}=I_{0}\left[\exp \left(\frac{V+R_{s} I}{V_{t} a}\right)-1\right]
$$

With I0 the saturation current of the diode:

$$
I_{0}=\frac{I_{s c, n}+K_{I} \Delta_{T}}{\exp \left(\frac{V_{o c, n}+K_{V} \Delta_{T}}{a V_{t}}\right)-1}
$$

Isc, $\mathrm{n}$ is the nominal short-circuit current, Voc,n is the nominal open-circuit voltage. $\mathrm{KV}$ is the open circuit voltage / temperature coefficient, a is a constant of the diode, $\mathrm{Vt}$ is the thermal voltage of the panel: $\mathrm{Vt}$ $=$ NskT/q, where Ns is the number of cells connected in series, $\mathrm{k}$ is Boltzmann's constant, $\mathrm{q}$ is the charge of the electron. Rs is the series resistance of the cell (depends on the material used to construct the cell, its effect is more important in the voltage source operating region). $\mathrm{Rp}$ is the parallel resistor, its effect is greater in the current source operating region). In general, the values of the resistors are not given by the constructor and must be determined by iterative algorithms [3].

\subsection{Model of a photovoltaic filed}

A photovoltaic field with Npp panel in parallel and Nss panel in series is shown in Figure 2.

The output current is then: 


$$
I=I_{p p} N_{p p}-I_{0} N_{p p}\left[\exp \left(\frac{V+R_{s} \cdot\left(\frac{N_{s s}}{N_{p p}}\right) \cdot I}{V_{t} \cdot a \cdot N_{s s}}\right)-1\right]-\frac{V+R_{s}\left(\frac{N_{s s}}{N_{p p}}\right) I}{R_{p}\left(\frac{N_{s s}}{N_{p p}}\right)}
$$

The following table gives the parameters of the photovoltaic panel used in the following paragraphs. Iscn is the nominal short-circuit current at standard test conditions (STC) $\left(25^{\circ} \mathrm{C}\right.$ and $\left.1000 \mathrm{~W} / \mathrm{m}^{2}\right)$, Ipvn is the nominal current of the panel Ns is the number of cells (in series) for each panel, a is a constant of the diode, Npp is the number of modules connected in parallel, Nss is the number of connected modules In series.

Table 1. PV Panel Settings.

\begin{tabular}{cc}
\hline Parameter & Value \\
\hline Iscn & 5.96 \\
Ipvn & 6.10 \\
Vocn & 64.2 \\
$\mathrm{Ns}$ & 96 \\
$\mathrm{a}$ & 1.3977 \\
$\mathrm{Ki}$ & $0.065 \% /{ }^{\circ} \mathrm{C}$ \\
$\mathrm{Kv}$ & $0.080 \mathrm{~V} /{ }^{\circ} \mathrm{C}$ \\
$\mathrm{Npp}$ & 3 \\
$\mathrm{Nss}$ & 5 \\
\hline
\end{tabular}

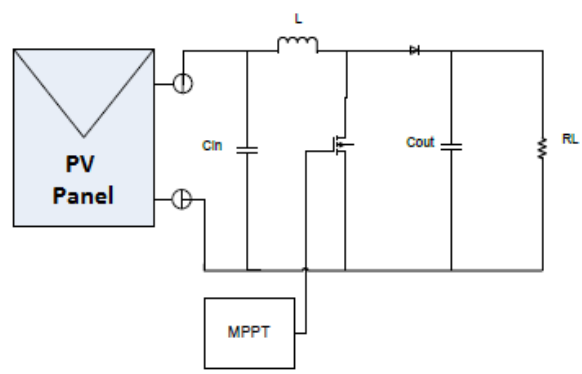

Figure 3. Configuring the PV System.

\section{Photovoltaic Field Control}

A photovoltaic field is the combination of several PV panels connected in series and parallel, the slightest defect on one of the panels can cause the performance degradation of the entire PV field [4-7].

That is why research has proposed an architecture or a controller is placed at each set of small numbered panels in order to manage the PV field decentrally. Despite the effectiveness of the proposed approach, the total cost of such an installation becomes unaffordable. Reason one considers in this work the architecture or a single control must manage the whole field PV.

\subsection{Configuring the Controller}

A DC / DC booster converter is used to obtain an output voltage higher than that provided by the PV field. The PV system studied is illustrated in Figure 3. Controller parameters are given in Table 2.

Table 2. Controller Settings.

\begin{tabular}{cc}
\hline aComponent & value \\
\hline Cin & $1 \mu \mathrm{F}$ \\
$\mathrm{L}$ & $0.005 \mu \mathrm{H}$ \\
Cout & $24000 \mu \mathrm{F}$ \\
RL & $100 \Omega$ \\
\hline
\end{tabular}




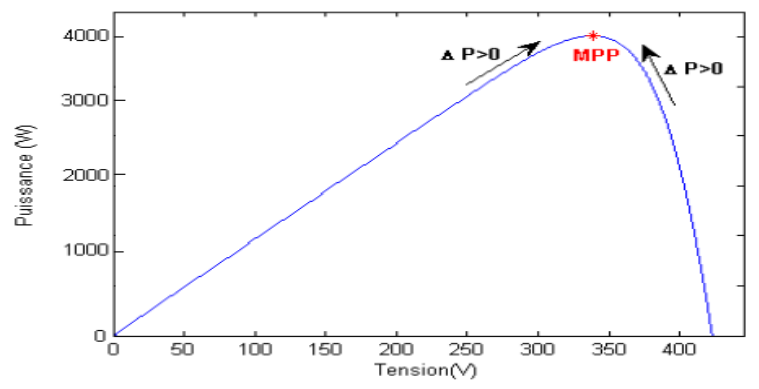

Figure 4. Characteristic Curve of a PV Panel.

\subsection{Control Algorithms}

1. P\&O algorithm:

Several algorithms have been proposed in the literature to extract the maximum power from PV installations. The simplest and fastest computational time algorithm is the $\mathrm{P} \& \mathrm{O}$ (Perturb \& Observe) algorithm which is based on the disturbance of the reference current to visualize the direction of power progression. Figure 4 illustrates the principle of this control, the objective is to reach the maximum power point (MPP) in a minimum of time[1-2].

The flowchart of the 'P \& O' command is given in Figure 5. The optimization algorithm requires the presence of a voltage and a current sensor to be able to identify the direction in which the power evolves.

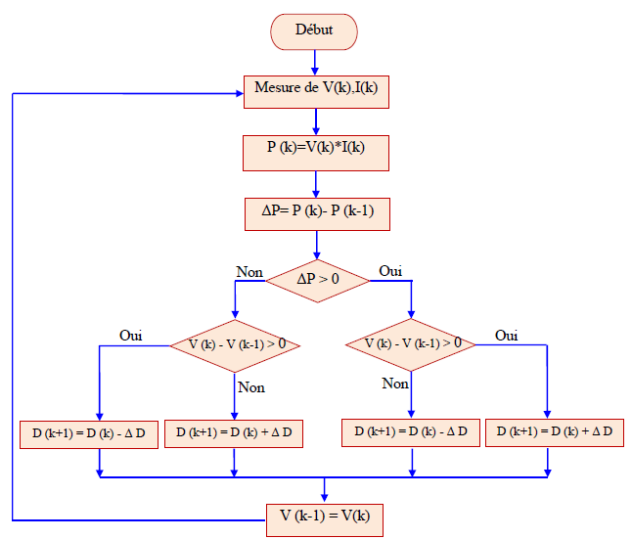

Figure 5. Flowchart of the P \& O optimization algorithm.

\section{Fuzzy Logic}

Fuzzy logic asserts itself as an operational technique. Used alongside other techniques for advanced control, it makes a discreet entrance but popular in industrial control automation. Fuzzy controller is divided into three steps illustrated in Figure 6.

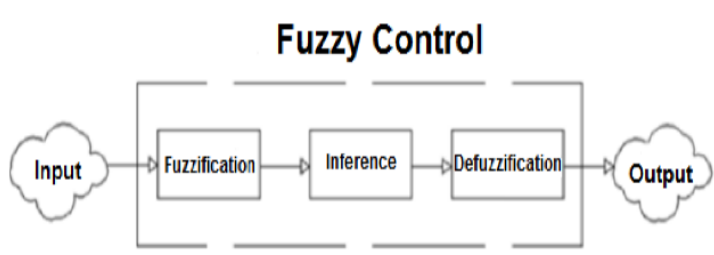

Figure 6. Steps of fuzzy control
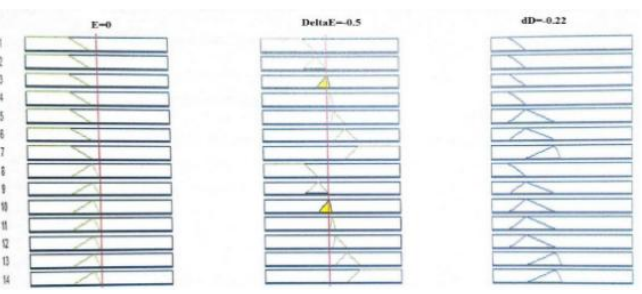

Figure 7. Numeric result obtained by inference block for $\mathrm{E}=0$ and $\Delta \mathrm{E}=0.5$ 
Fuzzication: This section transforms inputs into fuzzy variables. The inputs are transformed into linguistic variables described by membership functions. These functions can take many forms: triangular, trapezoidal, bell or other. This fuzzy controller uses trapezoidal and triangular membership functions. The input and output variables will be transformed to the following linguistic variables: 1. NG: Grand negative, 2. NM: Middle negative, 3. N: Negative, 4. ZE: Zero, 5. P: Positive, 6. PM: Middle positive, 7. PG: Grand positive.

Interference: It gives the relationship between input and output variables in language form. There are several methods of inference: MAX-MIN, MAX-PROD and SUM-PROD. Each method takes its own operators and each rule has the following form:

\section{If (Condition), Then (Conclusion)}

The method used by this fuzzy controller is the MAX-MIN method. In this method the operators AND, OR and Then are represented by the MIN and MAX.

Defuzzification: During this step, the result provided by the fuzzy inference output dD is converted to real value or numerical value. We distinguish several methods of defuzzification: the maximum method, the weighted average method, simplified method of centroid, the centroid method and others. The used method by the used fuzzy controller is the centroid method. This method will then convert the result of the fuzzy output variable $\mathrm{dD}$ to the duty ratio variations that will be acceptable by the converter. The centroid method calculates the center of gravity of the fuzzy surface obtained by the inference block (figure 7). [9]

\section{APPLICATION OF PSO ON MPPT}

To illustrate the application of the PSO algorithm in tracking the MPP using the improved technique

$$
\begin{aligned}
& v_{i d}^{k+1}=\omega v_{i d}^{k}+c_{1} r_{1}^{k}\left(P_{\text {best }_{d}}^{k}-x_{i d}^{k}\right)+c_{2} r_{2}^{k}\left(G_{\text {best }_{d}}^{k}-x_{i d}^{k}\right) \\
& x_{i d}^{k+1}=x_{i d}^{k}+v_{i d}^{k+1}
\end{aligned}
$$

the particle position $\mathrm{xi}$ is adjusted where the velocity component vi represents the step size, $\mathrm{w}$ is the inertia weight, $\mathrm{C} 1$ and $\mathrm{C} 2$ are the acceleration coefficients, $\mathrm{r} 1, \mathrm{r} 2 \in \mathrm{U}(0,1)$, Pbesti is the personal best position of particle, and Gbesti is the best position of the particles in the entire population. If position is defined as the actual duty cycle while velocity shows the perturbation in the present duty cycle, then can be rewritten:

$$
\begin{aligned}
& \phi_{i d}^{k+1}=\omega \phi_{i d}^{k}+c_{1} r_{1}^{k}\left(P_{b e s t_{d}}^{k}-d_{i d}^{k}\right)+c_{2} r_{2}^{k}\left(G_{\text {best }}^{k}-d_{i d}^{k}\right) \\
& d_{i d}^{k}=d_{i d}^{k}+\phi_{i d}^{k+1}
\end{aligned}
$$

In the case of PSO, resulting perturbation in the present duty cycle depends on Pbesti and Gbest. If If the present duty cycle (D) is far from these two duty cycles, the resulting change in the duty cycle will also be large, and vice versa. In the last, the perturbation in the D is always fixed but in PSO it varies according to the position of the particles. With proper choice of control parameters, a suitable Maximum power point tracking controller using PSO can be easily designed.

\subsection{MPPT for single peak}

First a solution vector of duty cycles with $\mathrm{Np}$ particles is determined, i.e:

$$
\begin{aligned}
& \mathrm{dg}=[\mathrm{d} 1, \mathrm{~d} 2, \mathrm{~d} 3, \ldots, \mathrm{di}] \\
& \mathrm{i}=1,2,3, \ldots, \mathrm{N}
\end{aligned}
$$

where dg is the duty cycle of the DC-DC convertor. The objective function is defined as:

$$
P\left(d_{i}^{k}\right)>P\left(d_{i}^{k-1}\right)
$$

$P\left(d_{i}^{k}\right)$ is the power for particle $\mathrm{i}$ at iteration $\mathrm{k}$, having a duty cycle. 


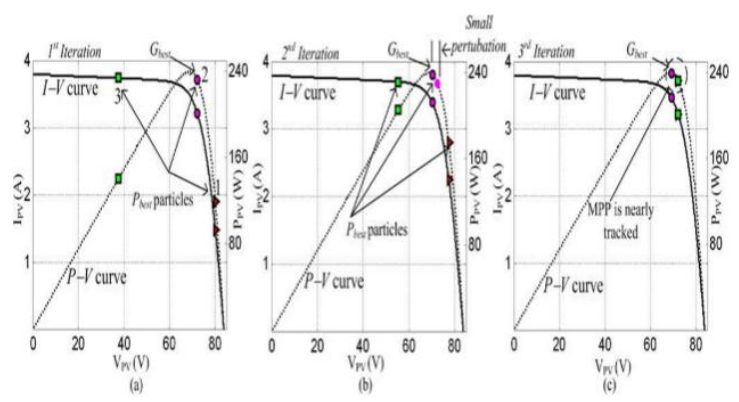

Figure 8. PSO particle movements in searching for the MPP

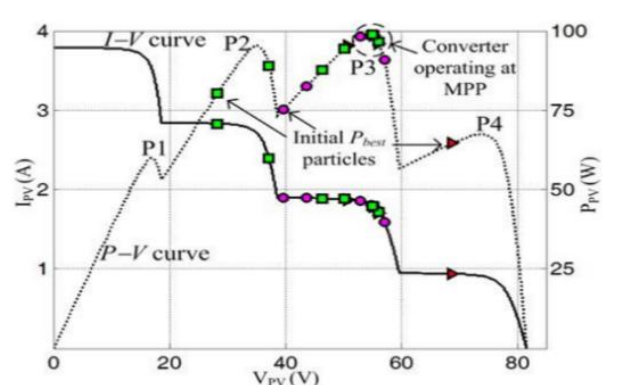

Figure 9. MPPT tracking by PSO during partial shading

The search process begins to transmits three duty cycles di $(i=1,2,3)$ to the power converter. In figure 8 , duty cycles $\mathrm{d} 1, \mathrm{~d} 2$, and $\mathrm{d} 3$ are indicated, with triangular, circular, and square points, respectively. in the first iteration, These duty cycles served as the Pbesti. Among these, $\mathrm{d} 2$ is the Gbest that offer the best fitness value, as illustrated by Figure 8(a). During the next iteration, the resulting velocity is only due to the Gbest term. The (Pbesti-d (i)) factor is zero. Moreover, the velocity of particle Gbest is zero due to the (Gbest- $\mathrm{d}(2)$ ) factor is zero. This results in a zero velocity and accordingly the $\mathrm{D}$ is unchanged. As a result, this particle will not effect in the exploration process. To avoid such situation, a small perturbation in D is allowed, as shown in Figure 8(b), to ensure the change in fitness value. Figure 8(c) present the particles movement in the third iteration. Due to the fact that all the $\mathrm{D}$ in the previous iteration attain a better fitness value, the velocity direction of these particles remains unchanged and subsequently they move toward Gbest along the same direction. In this iteration, all duty cycles $(\mathrm{di}, \mathrm{i}=1,2,3)$ arrive at Maximum Power Point with a low value of velocity. In the subsequent iteration, due to very low velocity, the value of the $D$ is approaching a constant. wherefore, the operating point will be keeped and the oscillation around the MPP diminishes.

\subsection{MPPT for multi-peaks}

When the photovoltaic array is operating in a uniform solar insolation, the resulting $\mathrm{P}-\mathrm{V}$ characteristic curve of the array exhibits a single maximum power point. However, under partial shading, the $\mathrm{P}-\mathrm{V}$ curves are characterized by multiple peaks, i.e., with several local and one global peak as depicted in figure 5. In this example, the $\mathrm{I}-\mathrm{V}$ curve is characterized by four stairs, while the $\mathrm{P}-\mathrm{V}$ curve is characterized by four peaks. The latter are labeled as P1, P2, P3, and P4. It can be observed that the time derivative of power $\mathrm{dP} / \mathrm{dV}$ is zero for the global as well as all the local peaks. Furthermore, the slope at its right and left sides has the same signs. Since all conventional MPPT methods are based on the slope and sign value of $\mathrm{dP} / \mathrm{dV}$, the algorithm could not distinguish the local (P1, P2, and P4) and global peaks (P3) correctly. It is very likely that the MPPT is being forced to trap into the local peak, resulting in reduced output power and thus greatly deteriorates the efficiency of the PV system[5-8].

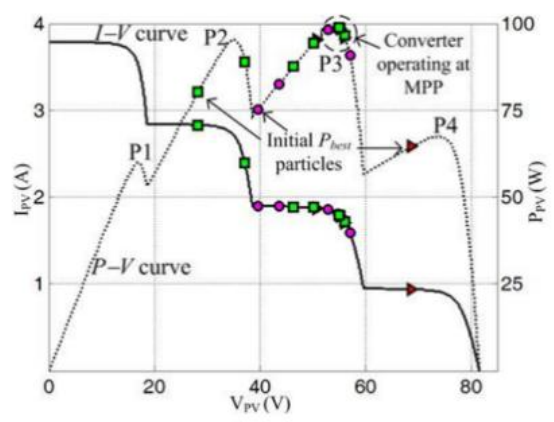

Figure 10. MPPT tracking by PSO during partial shading 
On the other hand, since the PSO method works on the basis of search technique, the global peak can be tracked without any difficulty. Figure 9 depicts the tracking capability of PSO during partial shading. Similar to the previous $\mathrm{P}-\mathrm{V}$ curve (see figure 8, the proposed method transmits three duty cycles, which serve as Pbest particles. It can be seen that the voltage and current contributing to these initial duty cycles (Pbesti) are away from the global peak (P3). But in the later phases of iterations, it successfully finds the global peak, P3.

\section{RESULTS AND ANALYSIS}

Figure 10 shows the SIMULINK model of the proposed system in single peak, figure 11 shows the SIMULINK model of the proposed system in multi-peaks.

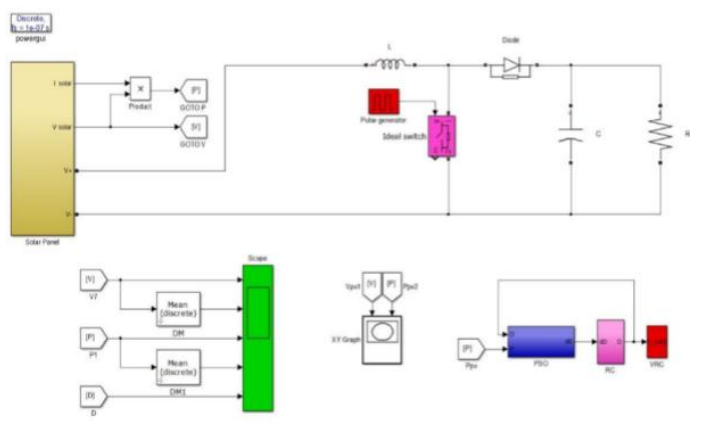

Figure 11. Diagram of complete system of PSO in single peak

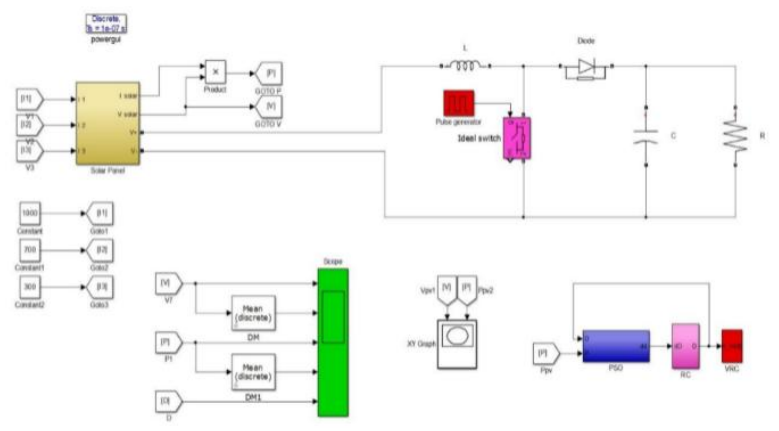

Figure 12. Diagram of complete system of PSO in multi-peaks

\subsection{Comparaison MPPT for single peak}

Figures 12, 13 and 14 illustrate the three models used for the different simulations. Figure 12 presents a load connected to PVG with the aid of boost type DC-DC converter but with a command MPPT of $\mathrm{P} \& \mathrm{O}$ type. Figure 13 presents the load connected to the same PVG but this time using the fuzzy command. Moreover, figure 10 shows the MATLAB/Simulink simulation model of the PV system used with the command of PSO type. SP (solar panel) is represented by a Simulink block, and DC-DC converter is already described above in figure 3. The frequency of the impulsions generator chosen is $40 \mathrm{kHz}$. The MPPT command block presents the used command, the block to block RC MPPT control the variation of the duty cycle, calculates the report and sends it to HRV function of "S-Function" type, which admits role of varying this ratio in the pulse generator.

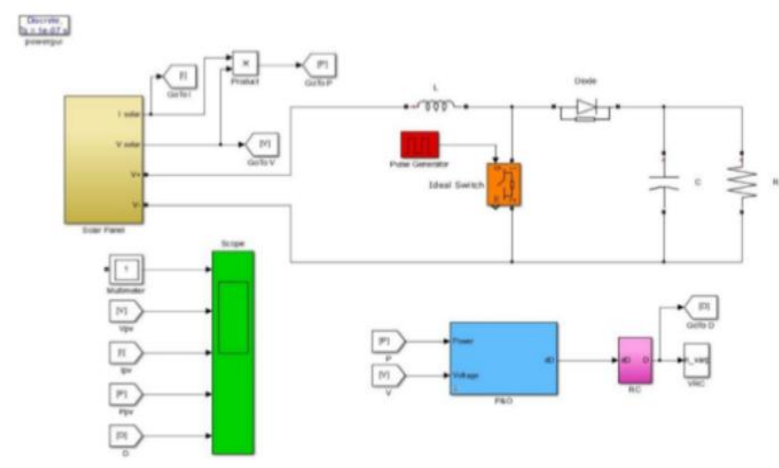

Figure 13. Connection with the $\mathrm{P} \& \mathrm{O}$ algorithm

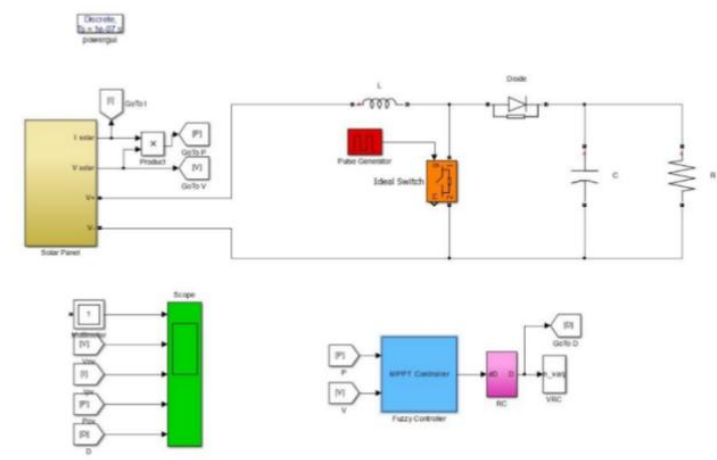

Figure 14. Connection using fuzzy control 


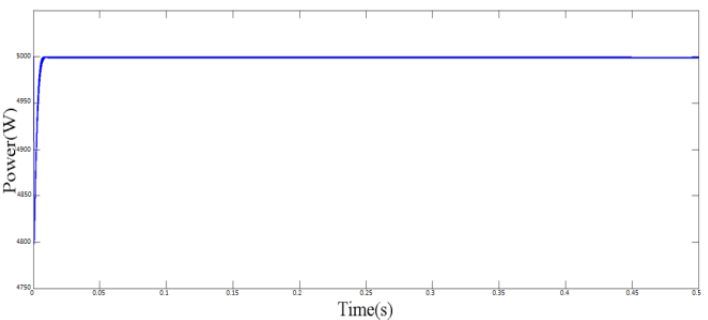

Figure 15. The maximum tracked power of the PV model using PSO algorithm

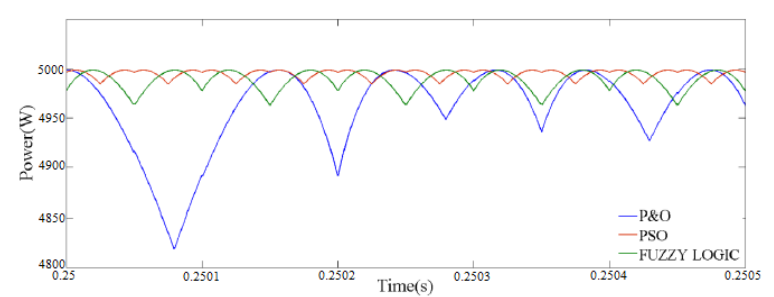

Figure 16. PSO, P\&O and fuzzy logic results in tracking the MPP

Figure 14 shows the variation of power of the SP as a function of time. We observe the effect of the applied PSO algorithm on the maximum power point, once the maximum power is reached the system stabilized at this value with an oscillation approximately equal to $8 \mathrm{~W}$. We will compare the obtained results of the PSO algorithm with the algorithm "P\&O" and the algorithm based on fuzzy logic. algorithms.

Figure 15 shows a comparison between the obtained power of the SP of PSO, P\&O and fuzzy logic

From the results obtained in figure 15 we can deduce that once the maximum power point is reached, the systems starts oscillating with a value of $200 \mathrm{~W}$ using $\mathrm{P} \& \mathrm{O}$ algorithm and 50W using fuzzy logic controller; however this oscillation decreases to $8 \mathrm{~W}$ using PSO. We can deduce that in tracking the MPP of the SP, PSO provides high accuracy more than the P\&O and fuzzy logic.

\subsection{MPPT for multi-peaks}

The role of PSO block is to lead the system to the MPPG (maximum power point global) with margin of a small error, and then stabilizes the system at the maximum. Figure 11 shows the diagram of complete system. We will do a comparison between the results gone using the PSO algorithm, and the results obtained from the neural-fuzzy logic controller. In this section, we present two different simulations. Insolation values of the two simulations will be given below.

\section{SIMULATION 1:}

Figure 4-13 shows the characteristic curve of PV system under the following insolation: E1 = 1000, $\mathrm{E} 2$ and $\mathrm{E} 3=700=300 \mathrm{~W} / \mathrm{m} 2$

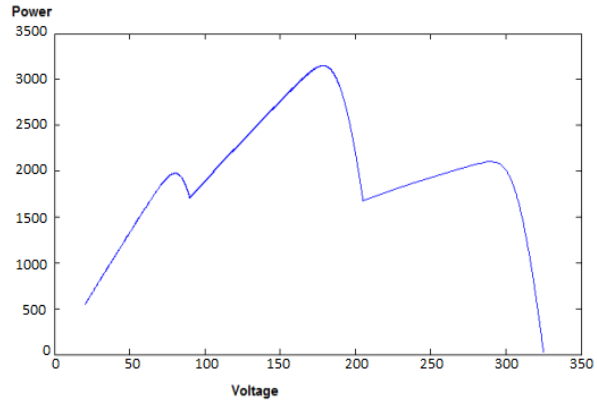

Figure 17. P-V characteristics of the first simulation

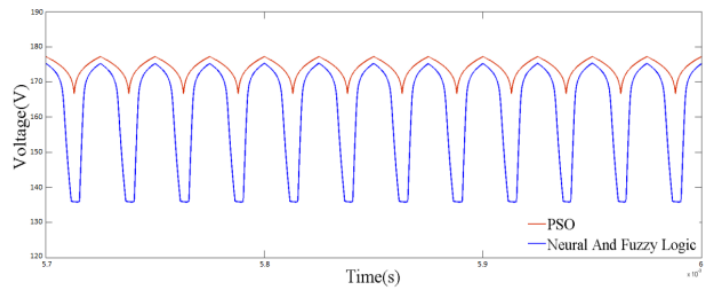

Figure 18. VPV of the first simulation compared to that obtained from Neural and fuzzy logic control 


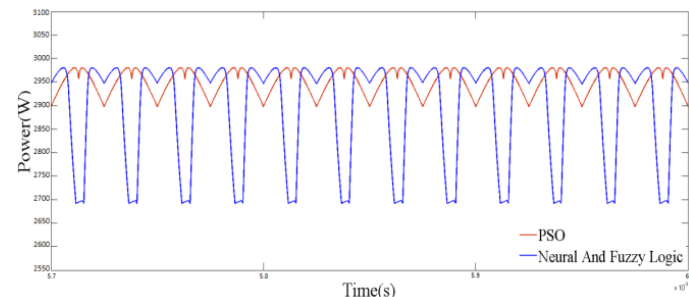

Figure 19. PPV of the first simulation compared to that obtained from Neural and fuzzy logic control

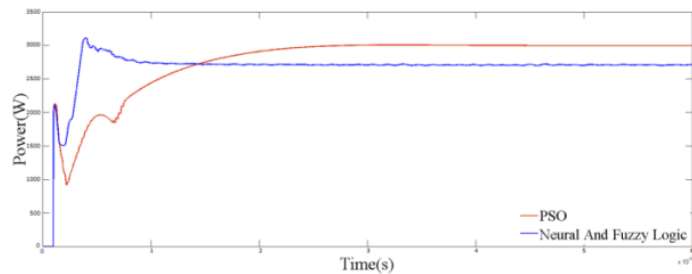

Figure 20. PPV(average) of the first simulation compared to that obtained from Neural and fuzzy logic control

\section{SIMULATION 2:}

Figure 4-17 shows the characteristic curve of photovoltaic PV system under the following insolation: $\mathrm{E} 1=750, \mathrm{E} 2=950$ and $\mathrm{E} 3=525 \mathrm{~W} / \mathrm{m} 2$

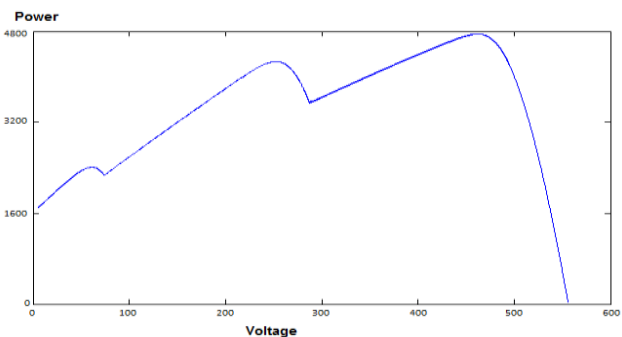

Figure 21. P-V characteristics of the second simulation

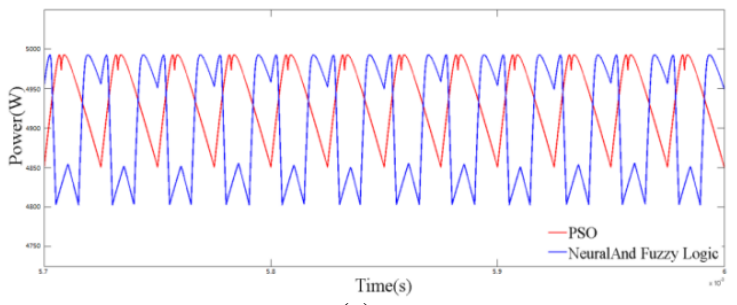

(a)

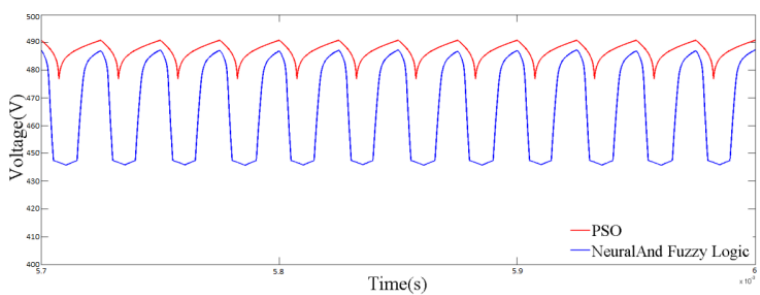

Figure 22. VPV of the second simulation compared to that obtained from Neural and fuzzy logic control

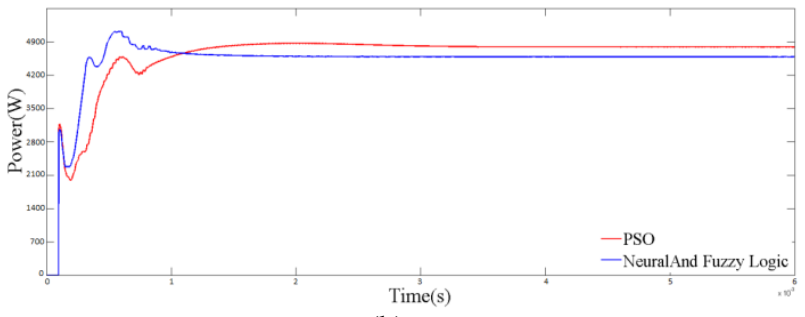

(b)

Figure 23. (a) PPV of the second simulation compared to that obtained from Neural and fuzzy logic control, (b) PPV(average) of the second simulation compared to that obtained from Neural and fuzzy logic control

Due to non-uniform solar insolation, the resulting P-V characteristic curve of the SP exhibits multipeaks as shown in figures 16 and 20. Figures 17, 18, 21, and 22 show the voltage and the power respectively of the PV panel obtained using the PSO algorithm compared to that obtained from the neural-fuzzy logic controller. We can deduce from these results that VPV variation using the neural-fuzzy logic controller is about $40 \mathrm{~V}$ in both simulations, where it is decreased by a considerable value using the PSO algorithm to $10 \mathrm{~V}$ in the first simulation and $12 \mathrm{~V}$ in the second. Moreover, we can make the same deduction for the PPV .Using neural-fuzzy logic controller, the power oscillation from the tracked maximum power point is $8000 \mathrm{~W}$ in the first simulation and $400 \mathrm{~W}$ in the second, where using the PSO algorithm it is $300 \mathrm{~W}$ in the first simulation and $200 \mathrm{~W}$ in the second. Figures 20 and 23 show the variation of the PPV(average) using PSO algorithm and neural-fuzzy controller. We can figure out that once the maximum power point $(3000 \mathrm{~W}$ in first simulation, $4900 \mathrm{~W}$ in the second simulation) is reached by the PSO, it is stabilized at this value; however, we can see in neural-fuzzy logic controller, once the maximum power point is reached, the system's power falls to a value $100 \mathrm{~W}$ less than the maximum power. 


\section{CONCLUSION}

This paper contains an approach of maximum power point tracking of photovoltaic systems based on particle swarm optimization algorithm. A particle swarm optimization (PSO) with the capability of direct duty cycle is used to track the MPP of PV system. A PV system, designed in MATLAB Simulink was used for the validation, in which a dc-dc boost converter was used as a MPP tracker. The performance of proposed controller is compared with "P\&O" and fuzzy-logic control algorithms. The total maximum power tracking using the PSO algorithm in this report gives a better result than the "P\&O" and fuzzy ones for single-peak MPPT, which is proved by simulation experiments in this report.

In the case of partial shading of PV array the output characteristics presents a number of extreme points. With the consideration of the good performance of the PSO in multi-peak function optimization, global optimization, as well as multi-variable optimization, the PSO algorithm is applied to the MPPT control algorithm. The used PSO algorithm can fast and accurately realize the MPPT in PV systems, and this was proved by the simulation results on MATLAB compared to that obtained by the neural-fuzzy control algorithm. However, there are still many areas for improvement for the PSO algorithm to make it easy applicable in many domains especially control.

\section{REFERENCES}

[1] Bennis, G., Karim, M., \& Lagrioui, A. (2015, December). Optimization of the performance of a photovoltaic system with MPPT controller. In 2015 3rd International Renewable and Sustainable Energy Conference (IRSEC) (pp. 1-6). IEEE

[2] Ghita, B., Mohammed, K., Ahmed, L., Nada, Z., Nourddine, S., \& Ayoub, E. (2016). Ortimization and modeling of a given PV system has a single phase load. Journal of Theoretical \& Applied Information Technology, 86(1).

[3] Emery, K.; Burdick, J.; Caiyem, Y.; Dunlavy, D.; Field, H.; Kroposki, B.; Moriarty, T.;Ottoson, L.; Rummel, S.; Strand, T.; Wanlass, M.W.; "Temperature dependence of photovoltaic cells, modules and systems

[4] Durgadevi.A, Arulselvi.S and Natarajan.S, "Study and implementation of maximum power point tracking (MPPT) algorithm for photovoltaic systems," in Electrical Energy Systems (ICEES), 2011 1st International Conference on, Pages. 241-244.

[5] M. Miyatake, M. Veerachary, F. Toriumi, N. Fujii, and H. Ko, "Maximum power point tracking of multiple photovoltaic arrays: A PSO approach,” 2011. IEEE Trans. Aerosp. Electron. Syst., Pages. 367-380,

[6] Patel, H. and Agarwal, V. Maximum Power Point Tracking Scheme for PV Systems Operation Under Partially Shaded Conditions. IEEE Trans. On Industrial Electronics, 55, 4, 1689-1698, 2008.

[7] Quaschning, V. and Hanitsch, R. Numerical simulation of current-voltage characteristics of photovoltaic systems with shaded solar cells. Solar Energy, 56, 6, 513-520, 1996.

[8] Villalva, M. G., Gazoli, J. R. and Filho, E. R. Comprehensive Approach to Modeling and Simulation of Photovoltaic Arrays. IEEE Trans. On Power Electronics, 24, 1198-1208, 2009.

[9] Tafticht, T., \& Agbossou, K. (2004, May). Development of a MPPT method for photovoltaic systems. In Electrical and Computer Engineering, 2004. Canadian Conference on (Vol. 2, pp. 1123-1126). IEEE 